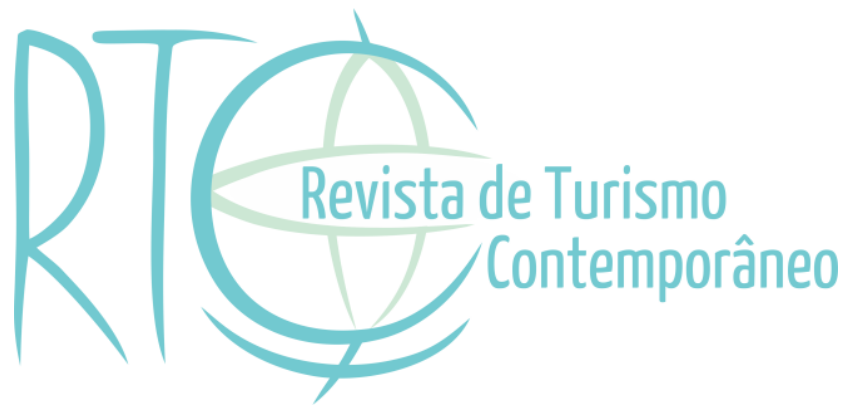

\title{
A percepção dos colaboradores de um hotel da capital paraibana sobre a política de recrutamento e seleção
}

\section{The perception of employees of a hotel in the capital of Paraiba on the politics of recruitment and selection}

Thales Batista de Lima

Professor adjunto II do DCSA/CCAE da Universidade Federal da Paraíba - UFPB, Mamanguape/PB, Brasil

E-mail: thalesufpb@gmail.com

Elisângela Vieira da Silva Amaral

Bacharel em Hotelaria pela Universidade Federal da Paraíba - UFPB, Mamanguape/PB, Brasil

E-mail: elisangelavieirasamaral@gmail.com 


\section{RESUMO}

A essência da hotelaria está na prestação de serviços e para tornar bem-sucedido no mercado se faz necessário uma equipe de colaboradores qualificados e bem preparados. Assim, o objetivo geral deste trabalho é analisar a política de Recrutamento e Seleção exercido por um hotel em João Pessoa- PB, a partir da percepção de seus funcionários. De tal modo, foram abordados os principais conceitos de Recrutamento e Seleção, bem como as fontes de recrutamento comumente mais utilizadas, as técnicas de seleção e as contribuições que o processo seletivo pode trazer para as organizações. Quanto à caracterização desta pesquisa, tratou-se de um trabalho de abordagem quantitativa, cujo método utilizado foi o dedutivo e classificado como estudo caso. Sendo assim, os resultados mostraram que o hotel estudado utiliza regularmente das políticas de Recrutamento e Seleção, além de contar com um departamento de Recursos Humanos próprio, que possibilita um olhar atento a esta política de entrada de novos funcionários. Porém, se torna interessante para o hotel rever algumas das suas práticas, como a maneira de divulgação de suas oportunidades, a frequência na aplicabilidade de provas situacionais e as etapas de dinâmica em grupo para visar o aperfeiçoamento sobre os conhecimentos dos candidatos. Conclui-se que o hotel pesquisado apresenta uma política de Recrutamento e Seleção, porém, requer ajustes para não comprometer uma melhor qualidade de seu desempenho na organização.

Palavras chaves: Recrutamento e Seleção. Hotel. Desempenho Organizacional.

\section{ABSTRACT}

The essence of hospitality is to provide services and to become successful in the market requires a team of qualified and well-prepared employees. Thus, the general objective of this work is to analyze the effectiveness of the Recruitment and Selection policy exercised by a hotel in João Pessoa, PB, from its employees. Thus, the main concepts of Recruitment and Selection, as well as the most commonly used sources of recruitment, the selection techniques and the contributions that the selection process can bring to the organizations were addressed. Regarding the characterization of this research, it was a work of quantitative approach, whose method used was the deductive and classified as a case study. Thus, the results showed that the hotel studied regularly uses Recruitment and Selection policies, as well as having a Human Resources department of its own, resulting in a good organizational performance. However, it is interesting for the hotel to review some of the policies, such as the way of publicizing its opportunities, the frequency in the applicability of situational tests and the stages of group dynamics in order to improve the candidates' knowledge. It is concluded that the researched hotel presents a Recruitment and Selection policy, however, it requires adjustments so as not to compromise the effectiveness of its organizational performance.

Keywords: Recruitment and Selection. Hotel. Organizational Performance. 


\section{INTRODUÇÃO}

O mercado de trabalho vem se tornando cada vez mais amplo e competitivo, o que torna a escolha de uma boa equipe de colaboradores uma missão bastante complexa, já que toda organização busca por pessoas qualificadas e preparadas para cumprir sua função. Para tanto, é necessário que se sucedam alguns processos de localização e captação de pessoas aptas a ocuparem os cargos disponíveis no mercado, já que para a submissão do recrutamento são necessários profissionais qualificados e inteirados da utilização de recursos existentes para a seleção de bons candidatos, sem desperdiçar tempo ou dinheiro (Ferreira \& Soeira, 2013).

Após a composição do recrutamento, tem-se início a seleção que é um processo mais complexo e restrito, pois se trata de uma atividade de filtragem, classificação, escolha e decisão (Chiavenato, 2008). Mesmo que sejam pronunciadas em conjunto, o recrutamento e a seleção apresentam atividades distintas. O êxito de uma organização, sobretudo, do meio hoteleiro, que é área de serviços, requer colaboradores capacitados e empenhados em desenvolverem suas atividades junto à organização visando a excelência no desempenho organizacional.

Brandão (2011) acrescenta que, em um hotel, a presença de políticas de recursos humanos torna-se fundamental para qualificar o ambiente de trabalho e auxiliar nos alcances estratégicos do negócio da organização para seu crescimento e fomento social. Doravante, esta política ainda requer de uma maior atenção em sua utilização por parte do setor hoteleiro, pois um estudo realizado em 2014 explicita que 53\% dos hotéis pesquisados em uma cidade de São Paulo desenvolvem a política de recrutamento e seleção por meio de gerente, e não de um profissional preparado para esta atividade. Além disso, em 60\% não existe sequer o setor específico da gestão de pessoas, uma vez que, em sua maioria, a gestão desses empreendimentos hoteleiros é de cunho familiar (Santaella, Santos \& Rodrigues, 2014).

Nesse sentido, é relevante estudos que detalhem de maneira mais minuciosa e aprofundada o uso desta política na hotelaria para uma melhor compreensão do tema e sua aplicabilidade, sobretudo, em meios de hospedagem. Portanto, este trabalho tem como objetivo analisar a política de Recrutamento e Seleção exercidos por um hotel em João Pessoa- PB, a partir da percepção de seus funcionários. 


\section{DESDOBRAMENTOS DO RECRUTAMENTO E SELEÇÃO PARA O SETOR HOTELEIRO}

As pessoas que se dedicam a trabalhar na hotelaria sabem que é uma área de serviços altamente dinâmica, heterogênea, cujo produto é intangível, perecível e sazonal. Assim, é preciso se preocupar com os perfis de seus funcionários para que estejam aderentes a esta realidade hoteleira (Barreto \& Lima, 2014). Nesse sentido, a política de recrutamento e seleção de pessoal retrata justamente o conhecimento destes perfis a fim de escolher os que mais se aproximarem dos perfis dos cargos a serem ocupados.

Salienta-se, ainda, que atrair turistas pressupõe a necessidade de pessoal preparado para criar, gerenciar e executar serviços. É nesse contexto que a gestão de pessoas ganha importância, pois a prestação de serviços ao hóspede é realizada pelo principal elemento que é o humano (Vieira, Lima \& Pereira, 2007). Segundo Barreto e Lima (2014), torna-se importante discutir as ações de gestão de pessoas em termos de benefícios mútuos, proporcionados para a organização e para o indivíduo. Até porque há uma necessidade de se estruturar e modernizar os sistemas de gestão de pessoas dos empreendimentos hoteleiros para garantir a sua sobrevivência no mercado cada vez mais competitivo.

Desse modo, alguns autores, como Marras (2011), cita o recrutamento e seleção como sendo um subsistema de recursos humanos $(\mathrm{RH})$, responsável pela captação e triagem de profissionais no mercado de seleção e encaminhamento de profissionais para a empresa. $\mathrm{E}$ acrescenta ainda que esse subsistema pode ser administrado por um único profissional ou por diversas equipes, levando em consideração o quadro funcional da organização.

Para Ferreira e Soeira (2013), toda empresa deve buscar pessoas qualificadas e preparadas para exercer sua função, por isto, deve realizar processos de busca e localização de pessoas adequadas para preencherem os cargos que estão disponíveis. E para a execução do recrutamento de pessoas é necessário um profissional qualificado e ciente de como utilizar os recursos disponíveis para a seleção de um bom candidato, sem desperdício de tempo e dinheiro, por exemplo.

O recrutamento é um processo de duas mãos: comunica e divulga oportunidades de emprego, ao mesmo tempo em que atrai os candidatos para o processo seletivo. A exemplo do que diz Chiavenato (2014), trata-se do processo de atrair um conjunto de candidatos para um cargo particular e deve anunciar a disponibilidade do cargo no mercado de trabalho e atrair candidatos qualificados para disputá-los. 
O recrutamento ocorre de duas maneiras: interna ou externamente, onde o interno trata dos candidatos que atuam dentro da organização, ou seja, seus próprios colaboradores, através de promoções ou transferências. Já o externo, atua sobre os candidatos dispostos no mercado de trabalho, fora da organização, submetendo-os ao seu processo de seleção de pessoal, conforme o quadro 1.

\section{Quadro 1: Recrutamento interno e recrutamento externo}

\begin{tabular}{|c|c|}
\hline \multicolumn{2}{|c|}{ RECRUTAMENTO } \\
\hline INTERNO & EXTERNO \\
\hline $\begin{array}{l}\text { - O preenchimento das vagas e das } \\
\text { oportunidades é feito através dos próprios } \\
\text { colaboradores atuais. }\end{array}$ & $\begin{array}{l}\text { - O preenchimento das vagas e das } \\
\text { oportunidades é feito pela admissão de } \\
\text { candidatos externos. }\end{array}$ \\
\hline $\begin{array}{l}\text { - Os colaboradores internos são os candidatos } \\
\text { preferidos. }\end{array}$ & $\begin{array}{l}\text { - Os candidatos externos são os candidatos } \\
\text { preferidos. }\end{array}$ \\
\hline $\begin{array}{ll}\text { Isso exige que sejam promovidos ou } \\
\text { transferidos para as novas oportunidades. }\end{array}$ & $\begin{array}{l}\text { Isso exige que sejam recrutados } \\
\text { externamente e selecionados para preencher } \\
\text { as oportunidades. }\end{array}$ \\
\hline $\begin{array}{l}\text { - A organização oferece uma carreira de } \\
\text { oportunidades ao colaborador. }\end{array}$ & $\begin{array}{l}\text { - A organização oferece oportunidades aos } \\
\text { candidatos externos. }\end{array}$ \\
\hline
\end{tabular}

Fonte: Adaptado de Chiavenato, 2014.

Doravante, após a estruturação do recrutamento, dá-se início a segunda fase do processo de contratação de pessoas, que é a seleção. O processo de recrutamento e seleção constituem-se um diferencial para as empresas que sabem escolher os indivíduos apropriados para o trabalho a ser executado, as quais identificam a importância da cooperação dos mesmos para o alcance de seus objetivos. As empresas, portanto, precisam atentar-se aos mecanismos empregados na seleção de candidatos, analisando se são coesos às pretensões da empresa e com os valores por ela difundidos (Ferreira \& Vargas, 2014).

O recrutamento e a seleção de recursos humanos devem ser tomados como duas fases de um mesmo processo: a introdução de recursos humanos na organização. "A seleção é a segunda etapa do processo, que começa com o recrutamento e termina com o contrato definitivo após o período de experiência. Uma boa seleção costuma considerar não só a vaga atual, mas o potencial do candidato" (Lacombe, 2005, p.79).

Segundo Marras (2000), o processo seletivo embasa-se diretamente na análise comparativa de dois campos: exigências do cargo e características do candidato. Onde o 
primeiro trata de características do profissional, referentes a conhecimentos, habilidades e atitudes exigidas pelo cargo que resultam em um bom desempenho nas funções. Já o segundo, trata dos conhecimentos, habilidades e atitudes próprias do candidato para desenvolver suas tarefas.

É sabido que alguns critérios devem ser observados antes da escolha de quais técnicas seletivas serão utilizadas para dar continuidade ao processo. Mas a questão é "quais os critérios devem ser utilizados na escolha dos métodos de seleção, se todos apresentam algum nível de subjetividade e são falíveis?" (Hanashiro, Teixeira \& Zaccarelli, 2007, p. 05).

A princípio pode ser citado o talento do selecionador, afinal cada selecionador tem seu próprio talento, onde uns acabam se destacando mais que outros. Alguns se destacam por conduzir boas entrevistas, que consequentemente fazem parte do processo seletivo.

Em seguida pode-se citar o sigilo do processo seletivo, pois conforme o cargo e o número de pessoas disponíveis no mercado serão necessários manter o sigilo da seleção, visto que os candidatos não queiram que os colegas do trabalho descubram que eles pretendem sair da empresa onde trabalham.

E por fim, outro critério a ser analisado, trata do número de candidatos $\mathrm{x}$ tempo a ser gasto x custo, quando a organização torna-se um grande atrativo, é comum que se tenha um numero um tanto exacerbado de candidatos, então trona-se necessário a escolha de técnicas que permitam a filtragem dos mesmos, aplicando primeiro as mais viáveis e que se permitam ser realizadas em menor espaço de tempo, já as que demandam maior tempo, custo e talento para serem empregados podem ser aplicados posteriormente (Hanashiro, Teixeira \& Zaccarelli, 2007).

Ferreira e Santos (2013) afirmam que as ferramentas de seleção são as técnicas utilizadas para observação e análise dos candidatos participantes do processo de seleção e comparar com os requisitos exigidos pelo cargo.

Após a obtenção das informações sobre o cargo e as competências necessárias, o próximo passo é a coleta de informações sobre os candidatos seguido da escolha de qual técnica de seleção objetivando o conhecimento, comparação e escolha dos candidatos mais adequado ao cargo. As técnicas de seleção podem ser agrupadas em cinco esferas como mostra o quadro 2: 
Quadro 2: As cinco esferas de técnicas de seleção

\begin{tabular}{|c|c|c|}
\hline ENTREVISTA DE SELEÇÃO & $\begin{array}{ll}\text { - } & \text { Entrevista dirigida } \\
\text { - } & \text { Entrevista livre (se }\end{array}$ & $\begin{array}{l}\text { iro preestabelecido) } \\
\text { definido) }\end{array}$ \\
\hline PROVAS DE & - Gerais & $\begin{array}{ll}\text { - } & \text { Cultura geral } \\
\text { - } & \text { Línguas }\end{array}$ \\
\hline CAPACIDADE & - $\quad$ Específicos & $\begin{array}{l}\text { - Conhecimentos técnicos } \\
\text { - Cultura profissional }\end{array}$ \\
\hline TESTES PSICOLÓGICOS & - $\quad$ Testes de aptidões & $\begin{array}{ll}\text { - } & \text { Gerais } \\
\text { - } & \text { Específicos }\end{array}$ \\
\hline \multirow{3}{*}{$\begin{array}{c}\text { TESTES DE } \\
\text { PERSONALIDADE }\end{array}$} & - Testes expressivos & - Psicodiagnóstico miocinético \\
\hline & - $\quad$ Testes projetivos & $\begin{array}{l}\text { - } \text { Psicodiagnóstico Rorscharch } \\
\text { - Teste da arvore } \\
\text { - Teste de apercepção temática }\end{array}$ \\
\hline & - Inventários & $\begin{array}{ll}\text { - } & \text { De motivação } \\
\text { - } & \text { De interesses }\end{array}$ \\
\hline TECNICAS DE SIMULAÇÃO & \multicolumn{2}{|c|}{$\begin{array}{l}\text { - } \quad \text { Psicodrama, dinâmica de grupo } \\
\text { - } \quad \text { Dramatização (role playing) }\end{array}$} \\
\hline
\end{tabular}

Fonte: Adaptado de Chiavenato, 2014.

A entrevista de seleção tem várias finalizações dentro das empresas, podendo ser aplicada desde a triagem inicial durante o processo de recrutamento, até o desligamento no processo de demissão de funcionários por exemplo. A entrevista pode ainda ser classificada como dirigida ou livre, onde respectivamente já têm um roteiro preestabelecido ou não.

As provas de conhecimento têm por finalidade medir qual o nível que o candidato tem de conhecimento a respeito do cargo o qual pretende ocupar. Trata-se de conhecimentos gerais e/ou específicos onde se enquadram o conhecimento de outras línguas, técnicas do cargo a ser ocupado, cultura geral e a cultura profissional da organização.

"Os testes psicológicos constituem uma medida objetiva e estandardizada de uma amostra do comportamento no que se refere a aptidões das pessoas". (Chiavenato, 2014; p. 134). Esses testes tomam por base amostras estatísticas de comparação e são aplicadas obedecendo um determinado padrão. Os testes psicológicos apresentam ainda, características que as entrevistas e provas tradicionais deixam passar por despercebidas. São elas:

I. Preditor: significa a capacidade de um teste oferecer resultados prospectivos capazes de servir como prognósticos para o desempenho futuro do cargo [...]

II. Validade: significa a capacidade do teste aferir exatamente aquela variável humana que se pretende medir $[. .$. 
III. Precisão: significa a capacidade do teste de apresentar resultados semelhantes em várias aplicações na mesma pessoa (Chiavenato; 2014; p. 135).

Os testes de personalidade tratam das características do candidato, que estão relacionados a seu caráter e temperamento. Geralmente são aplicados à seleção de cargos de alto nível, em virtude do custo e tempo de aplicação.

As técnicas de simulação tratam das dinâmicas de grupo e similares e até mesmo da simulação de eventuais conflitos que venham a ocorrer no cotidiano da organização.

Já Knapik (2008) trata das ferramentas (ou técnicas) de seleção como sendo um processo mais simples:

-Entrevistas de seleção: é onde o contato com o candidato torna-se mais próximo, por ser aplicada em qualquer momento do processo seletivo;

-Provas situacionais: essas objetivam identificar o comportamento do candidato diante de uma "situação real" no trabalho;

-Provas específicas: consistem em testar conhecimentos e competências relacionados à área de trabalho;

-Dinâmicas de grupo: são as técnicas vivenciais realizadas com um grupo de candidatos, por intermédio de exercícios específicos onde são observados determinados comportamentos dos participantes;

- Testes psicológicos, etc.: devem ser utilizados quando se quer traçar um perfil das características psicológicas dos candidatos.

Ferreira e Soeira (2013) acrescentam, ainda, que é interessante a utilização de mais de uma ferramenta de seleção, onde as mesmas devem "obedecer às especificações do cargo" (Ferreira \& Soeira, 2013, p. 54), o que consequentemente proporciona bons resultados no processo seletivo e também assegura que as competências do profissional estejam enquadradas aos objetivos da organização.

Por fim, há a seleção por competências, cujo modelo é uma das estratégias voltadas ao fortalecimento do vínculo entre as competências dos profissionais e objetivos da empresa. Envolve a contratação de colaboradores que se encaixam ao máximo do perfil do cargo a ser desempenhado. Para Ferreira Filho (2013), a seleção por competências tem por objetivo principal fornecer aporte forte, focado e explícito à escolha do profissional que melhor se enquadra ao cargo e a organização, sempre visando melhores resultados.

Já Pierry (2006, p. 69) trata da seleção por competência como sendo "instrumentos de avaliação da personalidade", referindo-se às técnicas (ou ferramentas) de seleção e, neste caso, as mais comumente utilizadas são: entrevista e dinâmica de grupos. Infelizmente alguns Revista de Turismo Contemporâneo - RTC, Natal, v. 6, n. 1, p. 66-89, jan./jun. 2018. 
profissionais desconsideram - por falta de conhecimento e/ou informação - tais técnicas, meramente acreditando que um único elemento venha a trazer as informações suficientes a respeito de determinado comportamento ou atuação do entrevistado.

Ressalta-se que há estudos que mostram avanços desta política dentro do campo organizacional ao fazer uso do ambiente virtual, embora em determinados locais a internet ainda seja subutilizada nas diversas etapas tanto do recrutamento quanto da seleção, como é o caso apresentado por Abreu et al (2014) que analisaram o uso da internet no processo seletivo de hotéis em Maceió e Salvador e evidenciaram a subutilização no seu uso, mesmo os gestores reconhecendo o potencial exercido pela internet. O não uso pleno do ambiente online nesta política pode ser de caráter financeiro, principalmente, no que se refere aos investimentos elevados e o retorno esperado (Araújo \& Ramos, 2002).

Entretanto, é uma tendência o uso de redes sociais na política de recrutamento e seleção, conforme explanam Gomes, Scherer e Lobler (2012) ao apontar vantagens e desvantagens no uso das redes sociais. Para eles, quanto ao recrutamento, as vantagens estão relacionadas à inexistência de custo, alcance do público jovem, fornecimento de um banco de dados para contato, abrangência e rapidez nesta fase. Já suas desvantagens foram a expansão do nome da empresa de forma negativa, poucas informações, abrangência em excesso. No que tange à seleção é entendido como vantajoso o complemento da imagem da pessoa e critério de desempate. Por outro lado, as desvantagens foram o risco de julgar, rotular pessoas, risco das pessoas "mascararem" um perfil, considerar em demasiado fatores pessoais, não ser uma verdade universal e nem todas as pessoas possuem as redes sociais.

Esses autores, contudo, frisam que "Embora o contato humano não seja substituído por essa tecnologia, ela serve como uma informação adicional para realização das etapas, além de não ter custo, ter uma ampla abrangência e obter rapidez nas informações" (Gomes; Scherer \& Lobler, 2012, p. 15).

Enfim, uma política de recrutamento e seleção se torna vantajoso para a organização quando bem desenvolvida, sobretudo, no âmbito tão dinâmico e volátil do setor hoteleiro, pois pode acrescentar à empresa habilidades, comportamentos e atitudes necessárias e prioritárias. Características essas que não seriam normalmente adquiridas ou desenvolvidas rapidamente pelo candidato por uma política de treinamento. Aliás, destaca-se a redução de custos que envolve uma seleção bem-sucedida para a organização, uma vez que a área de recursos humanos, provavelmente, terá menos dispêndios com o funcionário selecionado em termos de treinamento e desenvolvimento, por exemplo. 


\section{METODOLOGIA}

O trabalho adotou uma metodologia de abordagem quantitativa, que de acordo com Duarte (2013) é aquela que retrata tudo o que pode ser quantificável, ou seja, ela traduz em números as informações adquiridas para posteriormente, ao alcançar a análise dos dados chegar-se a uma conclusão.

O método utilizado foi o dedutivo, que de acordo com Pronadov e Freitas (2003) é aquele no qual parte de uma análise geral que tem por objetivo trazer as explicações particulares as quais fazem chegar a uma conclusão sobre determinado assunto. É uma pesquisa de natureza aplicada uma vez que se caracteriza pela busca de resultados práticos para possível aplicação no local pesquisado. Cervo, Bervian e Da Silva (2007) afirmam que cada pesquisa possui peculiaridade próprias, assim, na pesquisa aplicada o investigador é movido pela necessidade de contribuir para fins práticos, buscando solucionar questões mais concretas. Além disso, esta pesquisa é de cunho descritiva a qual tem a intenção de "escrever as características de um objeto de estudo" (Gonsalves, 2003, p. 66).

\subsection{Universo e Amostra}

O universo escolhido foram os colaboradores de um hotel de luxo localizado na orla de João Pessoa - PB, onde o mesmo atua no mercado há pouco mais de um ano. Atualmente o hotel vivencia mudanças em seu quadro funcional e conta com um total de 35 colaboradores.

Assim, a amostra utilizada para este estudo está representada por 20 colaboradores, visto que, no período de realização da coleta alguns funcionários estavam de férias ou folga e não puderam participar da pesquisa. O quadro a seguir descreve o perfil dos pesquisados.

Quadro 3: Perfil dos pesquisados

\begin{tabular}{|cccc|}
\hline \multicolumn{2}{c}{ UNIVERSO } & \multicolumn{2}{c|}{ AMOSTRA } \\
\hline CARGO & $\mathbf{N}^{\mathbf{0}}$ De Funcionários & CARGO & $\mathbf{N}^{\mathbf{0}}$ De Funcionários \\
\hline Almoxarife & 1 & Almoxarife & 1 \\
\hline Assistente de Eventos & 2 & Assistente de Eventos & 1 \\
\hline Auditor & 3 & Auditor & 2 \\
\hline Auxiliar de Cozinha & 2 & Auxiliar de Cozinha & 1 \\
\hline Auxiliar de Serviços & 2 & Auxiliar de serviços & 2 \\
\hline Gerais & 5 & Gerais & 1 \\
\hline Camareira & 1 & Camareira & Coordenador de \\
\hline Coordenador de & 5 & C n & 1 \\
\hline
\end{tabular}




\begin{tabular}{|cccc|}
\hline Manutenção & Manutenção & 0 \\
\hline Garagista & 2 & Garagista & 2 \\
\hline Garçom/Garçonete & 2 & Garçom/Garçonete & 1 \\
\hline Gerente de Recepção & 1 & Gerente de Recepção & 1 \\
\hline Governanta & 1 & Governanta & 1 \\
\hline Maître & 1 & Maître & 2 \\
\hline Mensageiro & 4 & Mensageiro & 2 \\
\hline Operador de Caixa & 1 & Operador de Caixa & 1 \\
\hline Recepcionista & 5 & Recepcionista & $\mathbf{2 0}$ \\
\hline Supervisor de Andares & 1 & Supervisor de Andares & TOTAL \\
\hline TOTAL & $\mathbf{3 4}$ & & (
\end{tabular}

Fonte: Hotel Pesquisado (2016).

\subsection{Processo de coleta e análise dos dados}

Foi utilizado um questionário estruturado com 20 perguntas para a realização da coleta de dados. Essa coleta foi realizada nos meses de agosto e setembro de 2016, na qual os questionários ficaram dispostos ao hotel estudado para, posteriormente, serem aplicados aos colaboradores e gestores. Após esse período os questionários foram recolhidos para a análise.

Frisa-se que a análise dos dados ocorreu por meio da estatística descritiva que, conforme Peternelli (2004), procura descrever e avaliar determinado grupo (amostra), sem que sejam tiradas conclusões ou deduções acerca de grupos maiores (população). Foram expostas através de gráficos que, segundo Cervo, Bervian e Silva (2007, p.130) integram "representações visuais de categorias, variáveis e tendências".

\section{RESULTADOS}

Segundo Chiavenato (2014), as atividades de recrutamento visam anunciar a disponibilidade de cargos no mercado de trabalho e atrair candidatos qualificados para disputá-los. Com base nisso e nas técnicas de recrutamento, buscou-se saber como os colaboradores se interessaram e fizeram contato com a empresa. 


\section{Gráfico 1: Interesse e Contato com a Empresa}

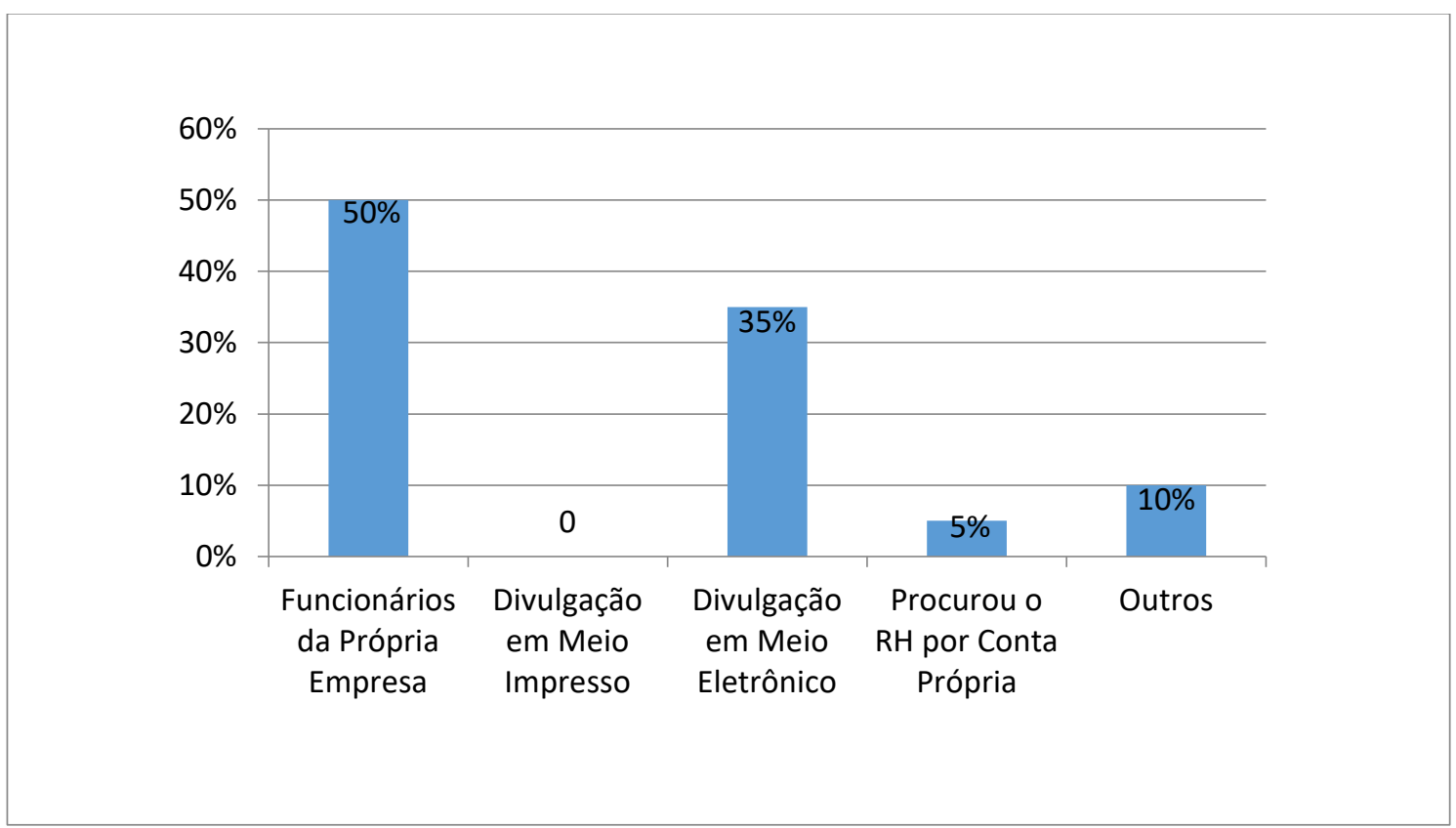

Fonte: Dados da Pesquisa, (2016)

O gráfico 1, mostra que as técnicas mais frequentes e que são mais utilizadas, representadas respectivamente por $50 \%$ e $35 \%$, são contato e indicação dos funcionários da própria organização e divulgação por meios eletrônicos. Com isso, pode-se deduzir, que mesmo com uma oferta significativa através de meios "modernos" de divulgação, a procura de empregos através da amizade e do coleguismo ainda é frequentes no mercado de trabalho.

Uma mínima parcela (5\%) dos entrevistados afirmou ter procurado o setor de $\mathrm{RH}$ da empresa por conta própria, e os demais souberam da disponibilidade de vagas através de amigos fora do hotel pesquisado e de "grupos de emprego" nas redes sociais. 
Gráfico 2: Ocupação do Mesmo Cargo Desde o Ingresso na Organização

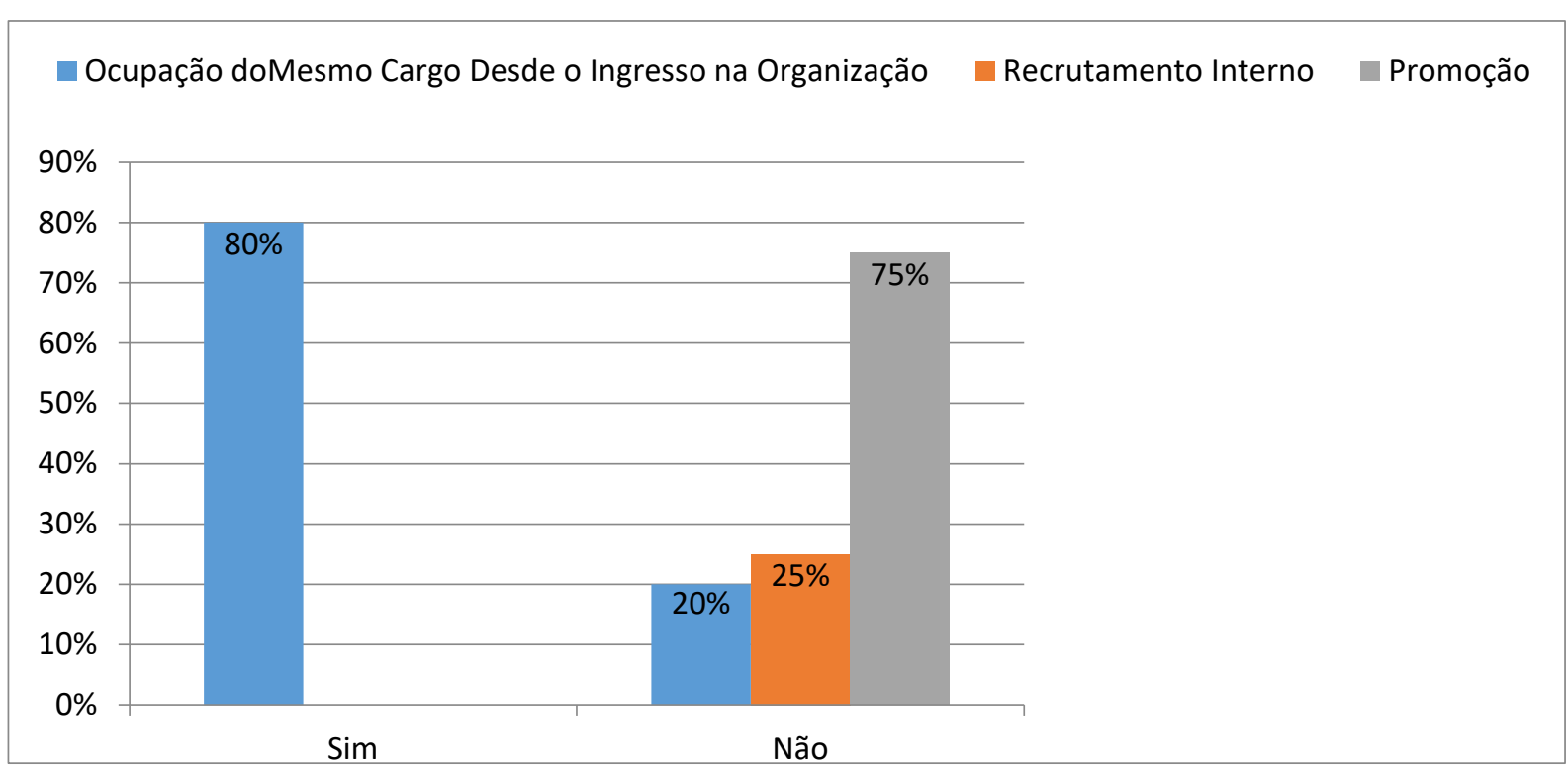

Fonte: Dados da Pesquisa, (2016)

Quanto a ocupar o mesmo cargo desde que ingressou na empresa, a maioria, $80 \%$, afirma não ter mudado de cargo, ainda assim pode-se observar a presença de fontes internas de recrutamento. Apesar de poucos terem mudado de cargo, o gráfico 2 explicita que a empresa está preocupada em fazer melhor aproveitamento do potencial humano, pois $75 \%$ dos entrevistados, em um total de $20 \%$, afirmaram terem sido promovidos, e os demais $25 \%$ passaram por recrutamento interno que, segundo Marras (2000, p.71), “é aquele que privilegia os próprios recursos da empresa".

Isso porque vagas em aberto são divulgadas nos quadros de avisos da organização, onde constam as aptidões impostas pelo cargo, pedindo que os candidatos interessados compareçam ao setor de recrutamento ou enviem seus dados para análise. Sendo assim motivados e encorajados a desenvolverem-se profissionalmente, e a sentirem-se incentivados a permanecer fidelizados a empresa em que trabalham. 


\section{Gráfico 3: Informação da Disponibilidade de Vaga Para o Cargo Ocupado}

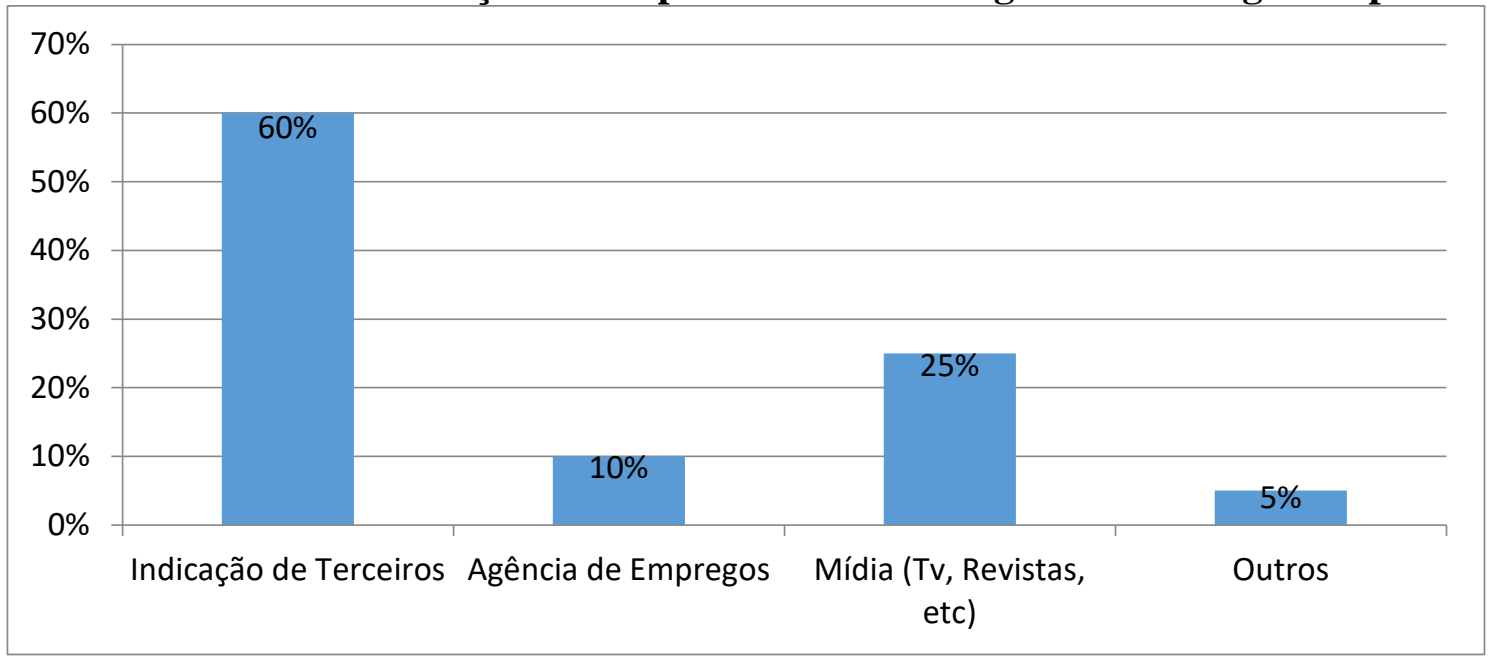

Fonte: Dados da Pesquisa, (2016)

Ainda tratando de fontes de recrutamento, ao serem indagados sobre como souberam da vaga para o cargo que ocupam, $60 \%$ afirmaram ter sido através da indicação de terceiros, o que inclui encaminhamento profissional, indicação de amigos, cartas de recomendação, etc. A segunda maior demanda, também representada no gráfico 3 , de $25 \%$ mostra que a informação foi passada através da mídia (classificados em jornais, rádio, revistas, Tv, e similares), apontando que a empresa preocupa-se em oferecer oportunidades através dos mais diversos meios de comunicação.

As atividades de recrutamento e seleção são compreendidas como um processo de agregar pessoas e embora sempre pronunciadas em conjunto, cada uma exige conhecimentos específicos. A unanimidade dos colaboradores ao afirmarem ter-se submetido à entrevista de seleção e entrega de currículo, demonstram, que o hotel estudado se faz ciente das políticas de recrutamento e seleção, cujas mesmas desempenham papeis distintos e que a aplicabilidade das mesmas se dá em setores diferentes. Brandão (2011) ressalta ainda que "cabe ao responsável pela gestão dos recursos humanos do hotel a incumbência de recrutar, selecionar, admitir, treinar, acompanhar, promover e demitir o pessoal que põe em funcionamento a empresa".

É a partir da entrevista que se tem um contato mais próximo com o candidato, por ser aplicada a qualquer momento durante o processo seletivo, e é através da mesma que a empresa conhece melhor a personalidade e o comportamento do entrevistado. Segundo afirma Chiavenato (2014) a entrevista funciona como instrumento comparativo, onde o entrevistador busca resultados coerentes medindo o que se pretende, exatamente, verificar. Dados da 
pesquisa demostram o quanto à organização preocupa-se em conhecer bem o seu capital humano.

Alguns pesquisados ainda acrescentaram o quanto à entrevista foi produtiva e esclarecedora, pois passava as informações acerca do funcionamento da empresa e do cargo a ser ocupado, outros ainda classificaram como "testadora da autoconfiança".

Brandão (2011, p.75) sobrepõe ainda, que "devido à necessidade de aperfeiçoar os recursos humanos, os funcionários de um hotel precisam ser recrutados, selecionados, treinados e orientados para produzirem os resultados esperados e atenderem as necessidades de cada hóspede”. Para tanto, faz-se necessário a utilização das ferramentas de seleção, as quais as técnicas utilizadas para analisar e observar os candidatos e fazer a comparação com os requisitos exigidos pelo cargo, de acordo com Knapik (2008) e Ferreira e Soeira (2013), auxiliam para um bom desfecho do processo seletivo, assegurando que as competências do profissional sejam enquadradas aos objetivos da organização. O hotel estudado faz uso de algumas dessas ferramentas, como demonstra a seguir.

Gráfico 4: Submissão a Provas Situacionais.

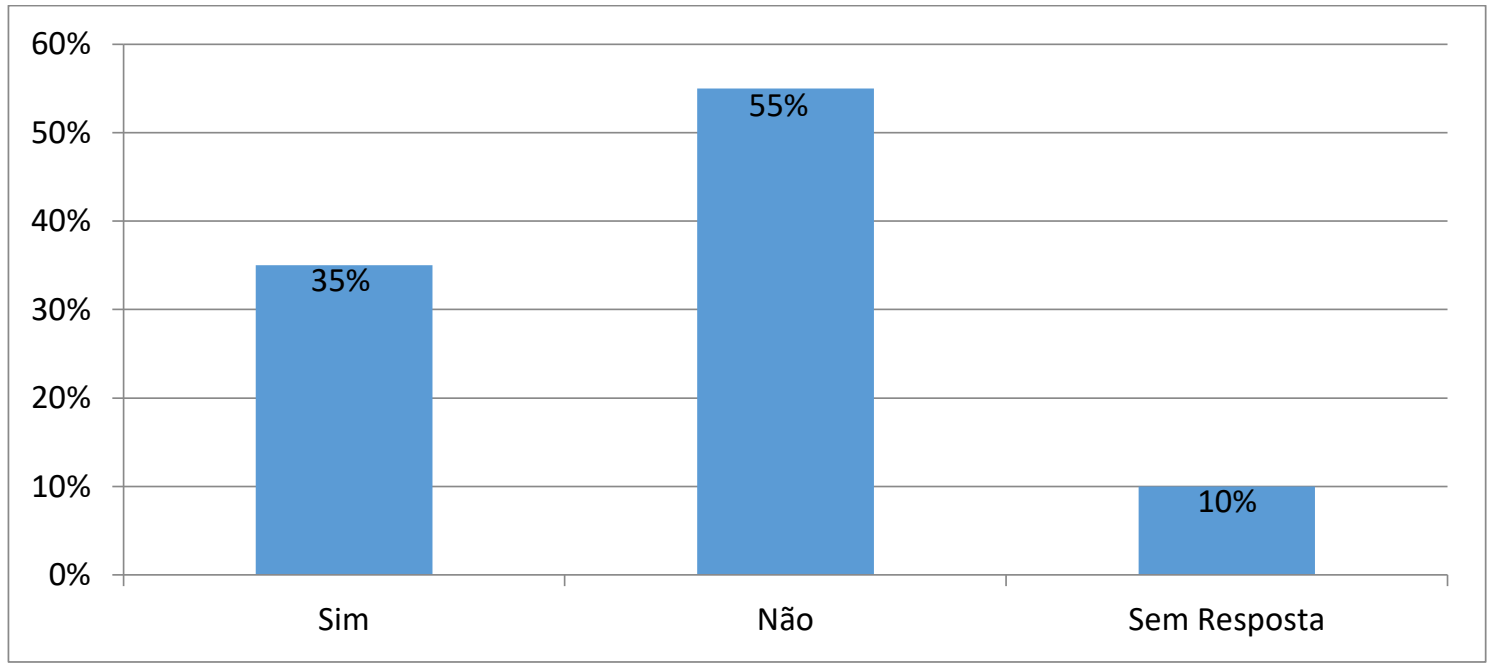

Fonte: Dados da Pesquisa, (2016)

As provas situacionais são aquelas em que o candidato é posto à prova diante de uma situação que venha a ocorrer no cotidiano da organização, além de saber o quanto o candidato está inteirado com a política da organização. O gráfico 4 exprime que a minoria, com 35\% dos entrevistados, foi submetida a tais provas, o que leva a pensar que a empresa tem autoconfiança no seu pessoal e nos serviços que oferta. Como também pode demonstrar a fragilidade do RH do hotel em conhecimentos específicos sobre melhores técnicas de seleção 
de pessoal para observar de forma mais aprofundada os comportamentos dos candidatos e, assim, poder escolher o que tenha demonstrado melhor preparo nas etapas seletivas.

\section{Gráfico 5: Etapas de Dinâmica em Grupo.}

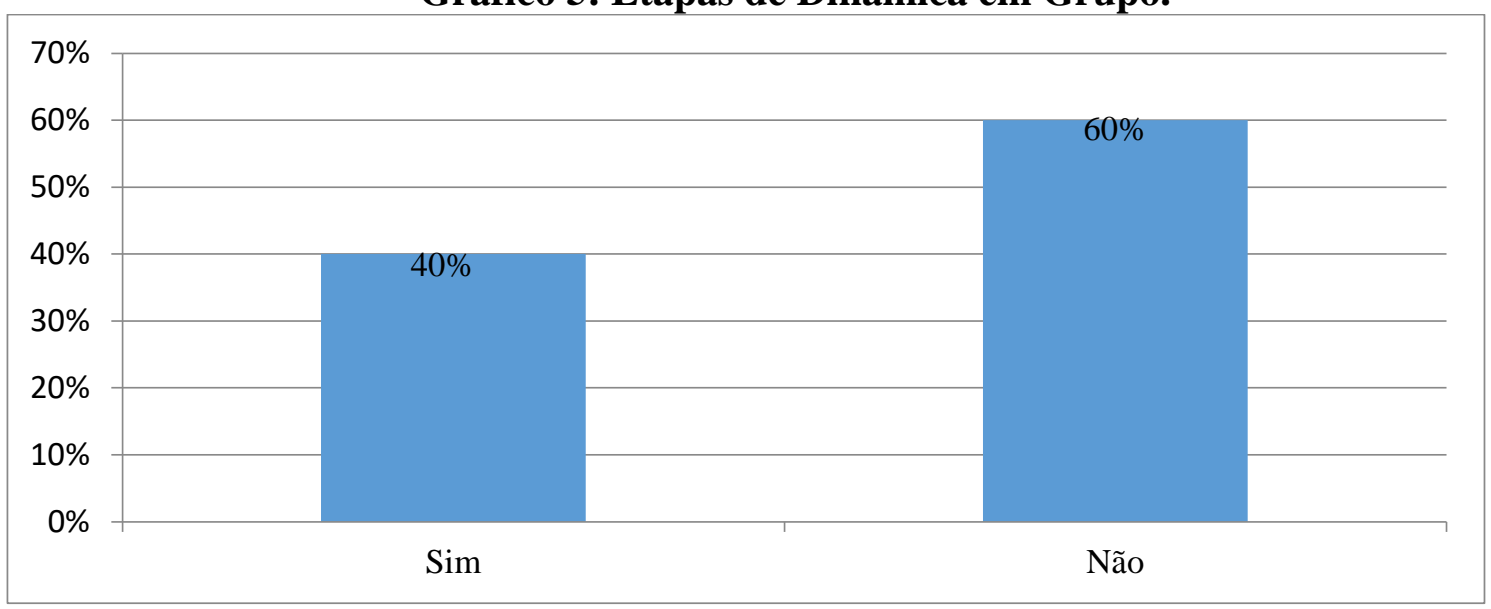

Fonte: Dados da Pesquisa, (2016)

Como visto no gráfico 5, etapas de dinâmica em grupo foram aplicadas a apenas $40 \%$ dos entrevistados. Essas dinâmicas são técnicas vivenciais realizadas com grupos de candidatos, através de exercícios específicos onde são observados os comportamentos dos participantes.

Sem contar o quanto se torna interessante aos candidatos, pois como um deles afirmou "podemos nos conhecer melhor". É interessante proporcionar essa interação aos candidatos para que possam construir um ambiente de trabalho regido por respeito e coleguismo mútuo. Pois como afirmam Hanashiro, Teixeira e Zaccarelli (2007), as dinâmicas em grupo tornam-se interessantes quando se pretende analisar a interação do indivíduo em grupo, buscando a percepção de como se relacionam e de como se impõem, inclusive a maneira que agem enquanto líderes. 


\section{Gráfico 6: Submissão a Testes Psicológicos.}

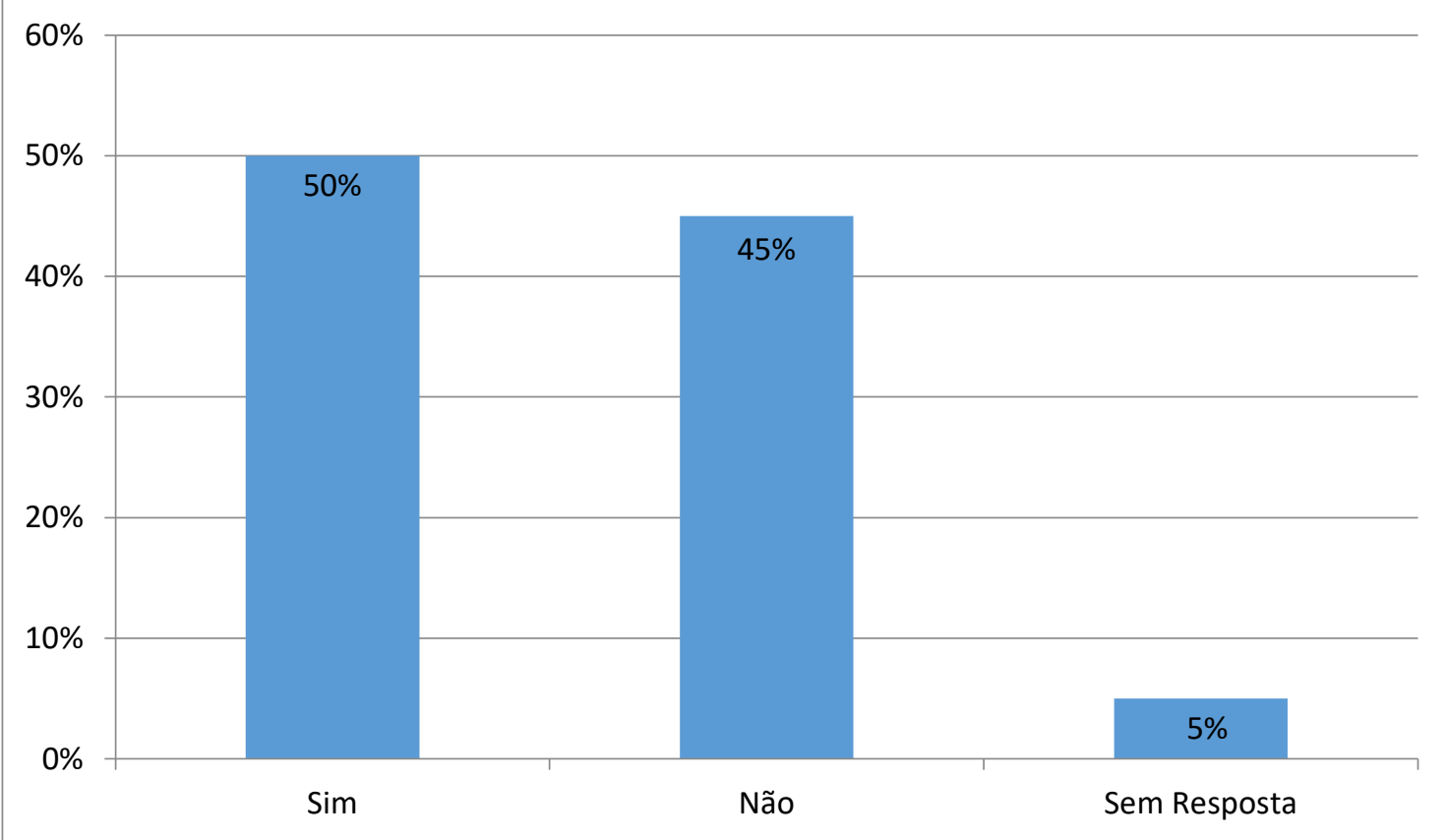

Fonte: Dados da Pesquisa, (2016)

Como pôde ser constatado no gráfico $6,50 \%$ dos colaboradores se submeteram a testes psicológicos. O que implica dizer que o hotel estudado se preocupa em traçar um perfil com as características psicológicas dos candidatos, tais como personalidade e temperamento, buscando assim montar uma equipe de colaboradores com o perfil mais "parecido" possível com a empresa.

Gráfico 7: Avaliação Pelo Setor de RH da Empresa.

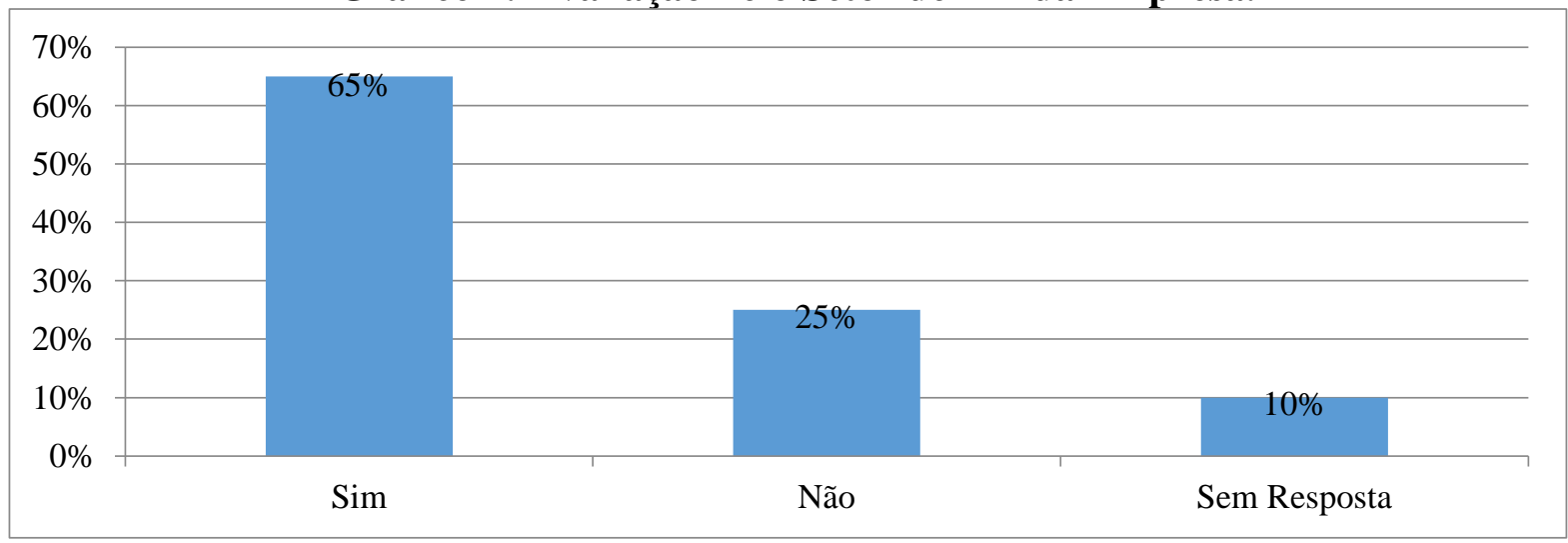

Fonte: Dados da Pesquisa, (2016)

O hotel objeto desse estudo conta com departamento de Recursos Humanos próprio. O que é bem notado pela representação do gráfico 7 , no qual $65 \%$ dos entrevistados 
afirmaram terem sido avaliados pelo RH do hotel, $10 \%$ não apresentou resposta e os $25 \%$ restantes foram avaliados pelo gerente geral e/ou pelo gerente de seus departamentos.

A seguir, o gráfico 8 explicita o quanto a organização se preocupa com o bem-estar e saúde física de seus colaboradores. Nota-se que $90 \%$ dos pesquisados confirmaram ter passado por avaliação médica. Por normas do hotel, foi solicitado o exame clinico geral.

\section{Gráfico 8: Solicitação de Avaliação Médica}

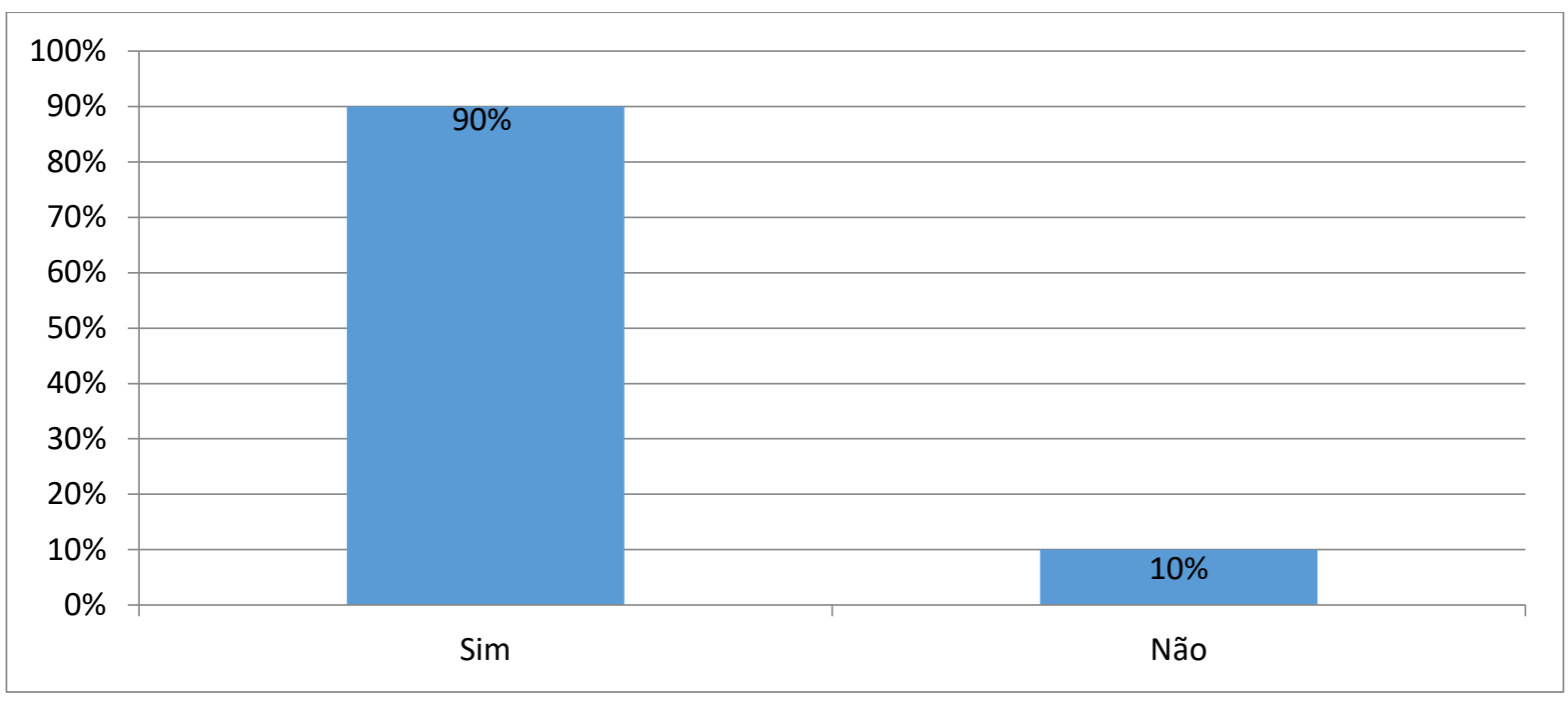

Fonte: Dados da Pesquisa, (2016)

Esse tipo de procedimento comumente solicitado em processos seletivos é importante tanto para a empresa como para o trabalhador e regido por duas vertentes: verificar se o candidato apresenta condições físicas para desempenhar suas atividades e preservar a saúde do trabalhador, verificando se há condições que possam se agravar com o trabalho.

Para tanto, Marras (2000) alega que devem ser realizados exames generalizados, complementados por exames laboratoriais (fezes, urina, sangue, entre outros) e radiografias, por que o laudo resultante desses exames irá implicar na contratação (ou não) do candidato, visto que podem ser apontadas características que impossibilite o colaborador - ou interfira no bom desempenho - de exercer suas atividades. 


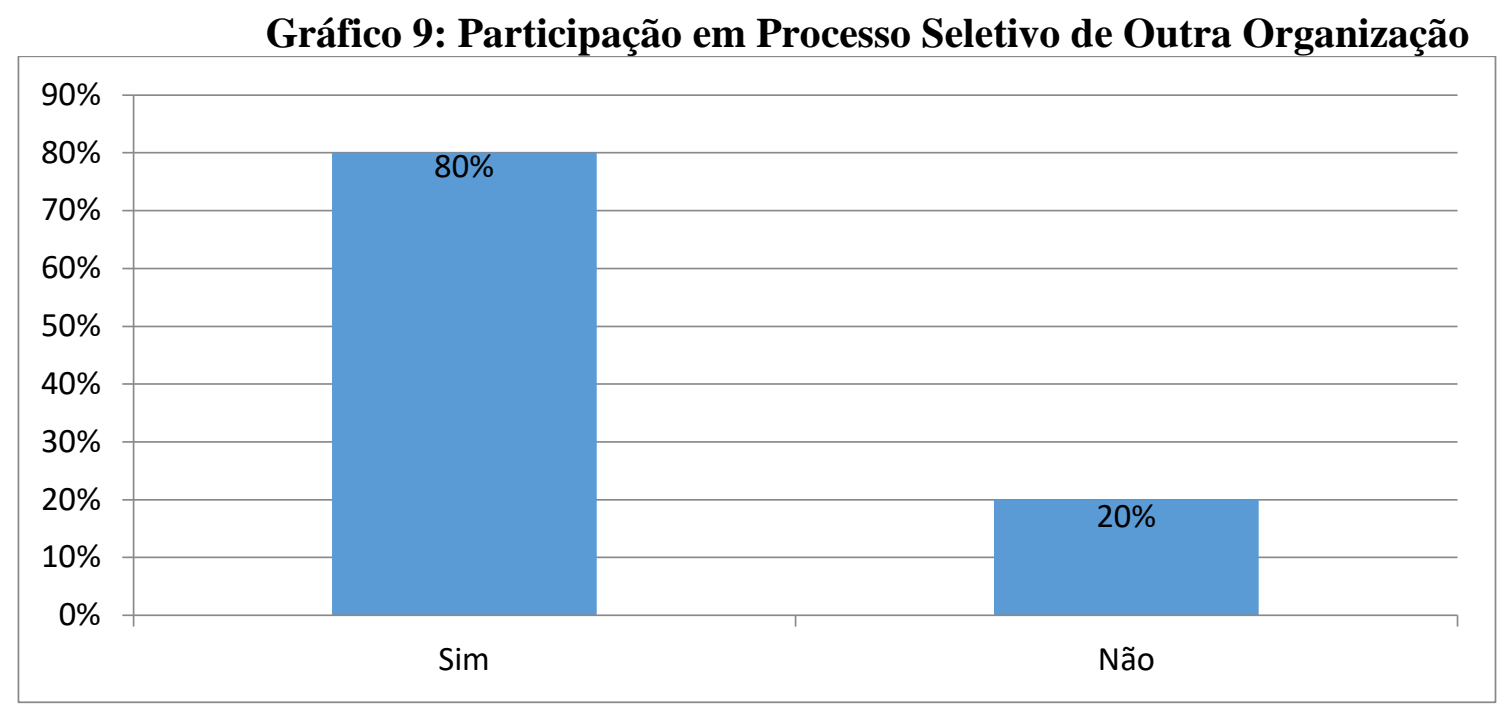

Fonte: Dados da Pesquisa, (2016)

Quanto à participação em processos seletivos de outras organizações, 80\% afirmaram já ter participado, o que indica que os $20 \%$ restantes possivelmente passaram pelo primeiro processo seletivo e estão em seu primeiro emprego. Os resultados podem ser tomados como suporte para a análise demonstrada no gráfico 10, o qual avalia a política de recrutamento e seleção da empresa estudada.

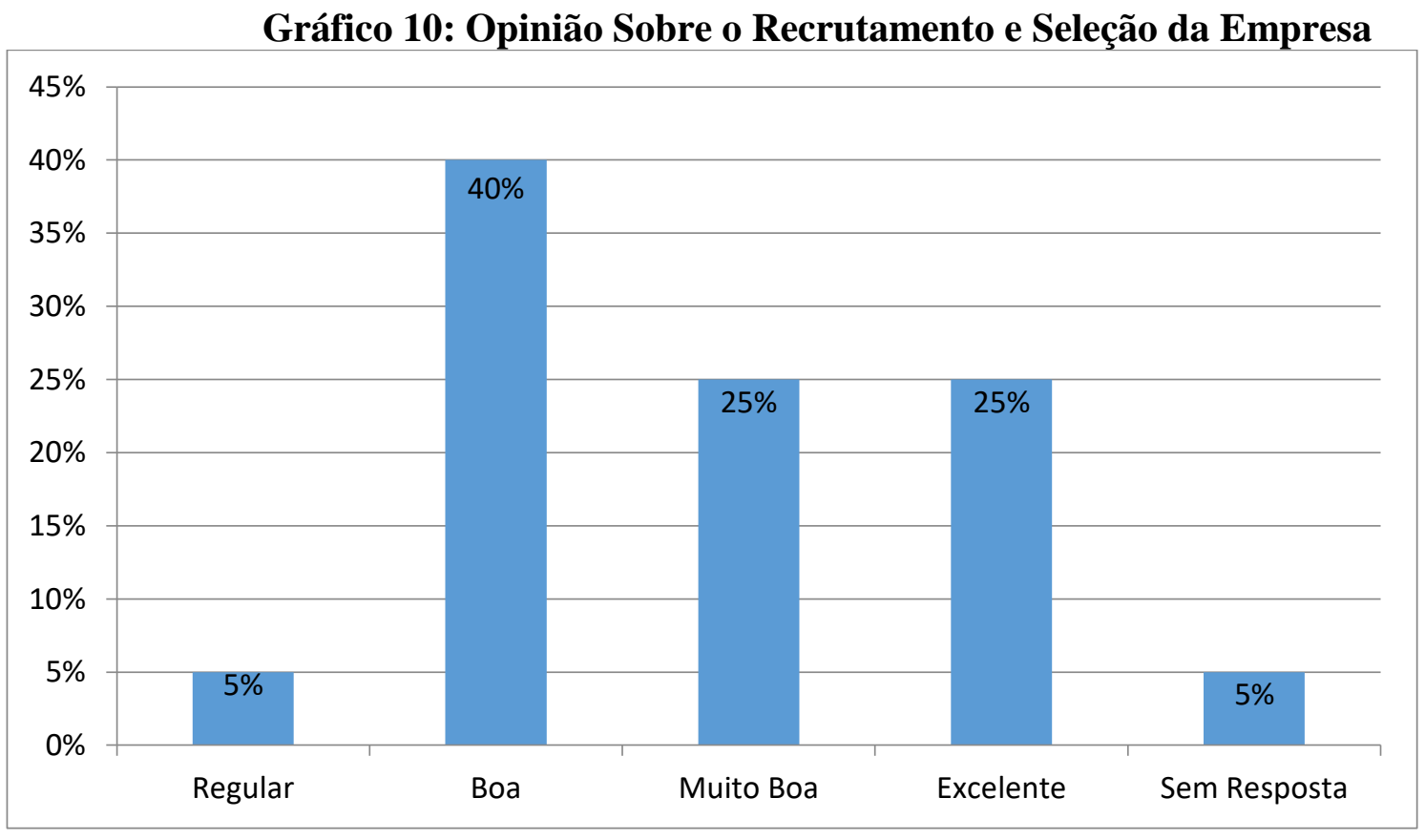

Fonte: Dados da Pesquisa, (2016)

Os dados acima revelam que a empresa está atenta em repassar aos seus colaboradores a melhor impressão possível desde o recrutamento, pois a política de recrutamento e seleção foi avaliada de boa a excelente. Alguns dos pesquisados ainda Revista de Turismo Contemporâneo - RTC, Natal, v. 6, n. 1, p. 66-89, jan./jun. 2018. 
justificaram suas respostas afirmando ser pelo aprimoramento com o qual a organização executa os procedimentos dessa política de recursos humanos, bem como pela maneira que buscam "conhecer bem seus colaboradores logo no primeiro contato".

Ao serem questionados sobre o que mais gostaram durante a seleção que passaram, por se tratar de uma questão aberta, as respostas foram as mais variadas possíveis, ainda assim houve uma repercussão acerca do método como a psicóloga da empresa conduzia a entrevista. Outro ponto bastante citado foi o fato da organização oferecer ao candidato liberdade de expressão e a objetividade e clareza das informações passadas e "da confiança que passaram com relação à empresa".

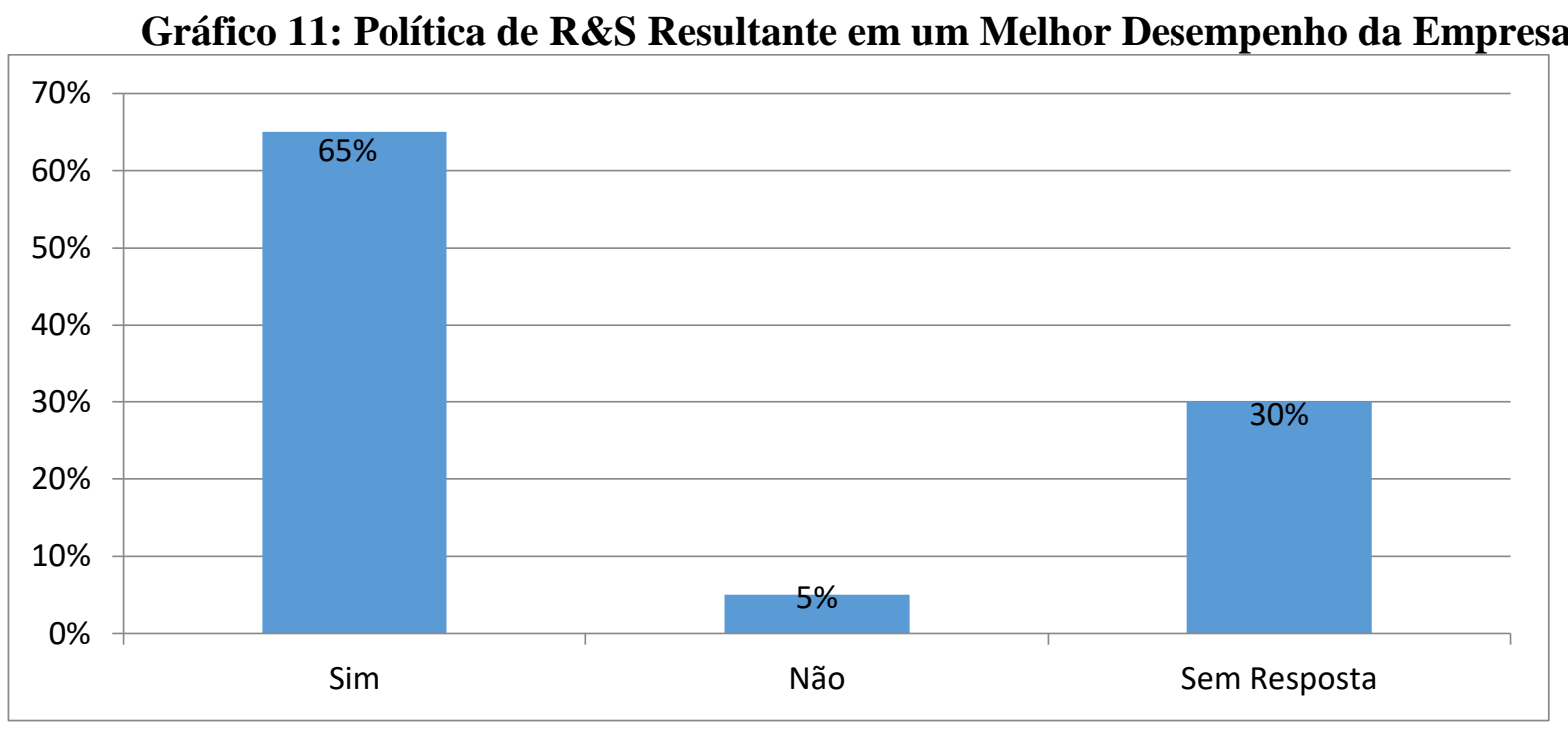

Fonte: Dados da Pesquisa, (2016)

A política de Recrutamento e Seleção quando bem utilizadas trazem benefícios para a organização. Percebe-se que a política utilizada tem impacto positivo para um alinhamento do candidato com as características requisitadas para determinado cargo da empresa, isto é, $30 \%$ dos entrevistados não apresentaram resposta, 5\% disseram que não influencia e a maioria, representada por $65 \%$, afirmou que tal política utilizada pelo hotel estudado afeta positivamente. Um dos pesquisados até argumentou que "eles buscam por pessoas qualificadas e que trazem benefícios tanto à empresa quanto a outros colaboradores".

Isto é, os participantes da pesquisa acreditam que esta política é bem desenvolvida pelo hotel, e que por apresentar profissionais condizentes com as características dos cargos acaba contribuindo possivelmente em um melhor desempenho do hotel. Enfim, a política de 
R\&S resulta em melhoria do desempenho do hotel pela visão dos respondentes por acreditarem que há profissionais qualificados e compatíveis com os cargos existentes.

Aliás, Cazotto, Cobero e Daolio (2016) acrescentam que adequar o candidato corretamente à sua função ajuda a reduzir os níveis de absenteísmo e rotatividade por estarem com profissionais qualificados para os cargos existentes e, provavelmente, resultando em melhorias no seu desempenho organizacional. Carvalho et al (2015) reforçam que a relevância do processo de recrutamento e seleção como forma de diminuição da rotatividade da organização. Assim, a política de recrutamento e seleção quando bem realizado pode diminuir a rotatividade e melhorar a produtividade e motivação da equipe, pois a pessoa certa estará no lugar certo.

Evidenciou-se, também, que o hotel estudado apresenta uma relação aberta e clara com seus funcionários, em que os mesmos além de comprometidos com suas funções, mostraram-se inteirados com a sistemática adotada pelo hotel, ao ponto de retratarem qual a metodologia exercida atualmente e quando a organização pretende contratar novos colaboradores. Salienta-se, conforme os funcionários pesquisados, que são divulgadas as vagas para os cargos que necessitam e, em seguida, dá-se continuidade aos procedimentos.

Sendo assim, o recrutamento de uma organização, quanto à contratação de novos profissionais, ocorre de acordo com sua necessidade, no qual Marras (2000) comenta que normalmente é emitida pelo requisitante do setor através de uma RP (requisição de pessoal). E notou-se a aplicabilidade de tal técnica no hotel estudado através do diálogo de um dos pesquisados: "é sinalizado para o setor de RH da necessidade da contratação, onde essa pessoa irá passar por seleção e treinamento antes de iniciar na sua jornada de trabalho”.

Portanto, o hotel estudado mostra-se com devido conhecimento acerca das diferenças existentes nas atividades de recrutamento e seleção, que mesmo sendo pronunciadas em conjunto, necessitam de conhecimento específicos em cada área. No entanto, torna-se plausível que o mesmo reveja alguns de seus procedimentos desta política, apenas, no intuito de aprimorar suas habilidades a respeito do que concerne ao recrutamento e à seleção de pessoal.

\section{CONCLUSÃO}

As políticas de Recrutamento e Seleção fazem-se necessárias, visto que são responsáveis pela entrada de capital humano na organização. Para tanto, alguns critérios podem ser considerados como, por exemplo, selecionadores que estejam a par das ferramentas e recursos disponíveis e necessários para selecionar um bom candidato, sem que haja 
desperdício de tempo e recursos financeiros. Afinal, o êxito de uma empresa depende também da qualidade de seus colaboradores e do quanto que estes estão adequados ao perfil dos cargos da organização e das estratégias organizacionais.

Assim, pôde-se observar na pesquisa que o hotel se utiliza de contato e indicação dos funcionários da própria organização, divulgação por meios eletrônicos, recrutamento interno, promoção, indicação de terceiros, mídia e entrega de currículo, cujas ferramentas podem ser classificadas como fontes internas e/ou externas de recrutamento.

A partir da presença de algumas das ferramentas de seleção, tais como: provas situacionais, entrevista de seleção, dinâmica em grupo, testes psicológicos, e avaliação médica, na qual são responsáveis pela observação, comparação e análise do candidato participante do processo seletivo, permitiu-se entender melhor os meios utilizados na realização do processo seletivo do hotel.

Por fim, foi possível verificar que tais políticas ocasionam impactos positivos no hotel estudado, uma vez que se mostra preocupado em buscar por profissionais bem estruturados, qualificados e com o perfil mais parecido possível com o perfil da empresa e do cargo que exercem, respectivamente.

Pode-se concluir que seria interessante que o mesmo, no intuito de aperfeiçoar conhecimentos acerca das políticas de Recrutamento e Seleção, revesse algumas de suas aplicações, a exemplo da maneira como divulga suas oportunidades, bem como maior frequência na aplicabilidade de provas situacionais e as etapas de dinâmica em grupo, visto que, a empresa se mostrou um tanto frágil nesse aspecto. Enfim, é um tema que suscita aprofundamentos para estudar tal política no meio hoteleiro, até para tomar melhor conhecimento do perfil do hoteleiro no mercado de trabalho e o quanto a sua formação profissional contribui para que estejam mais adequados às exigências das redes hoteleiras.

\section{REFERÊNCIAS}

Abeu, N. R. de. et al. (2014). E-recruitment no setor hoteleiro: cenário atual e potencialidades em Salvador e Maceió. Revista Perspectivas Contemporâneas, 9(2).

Araújo, S. F. de. \& Ramos, A. S. M. (2002). Recrutamento on-line: estudo da percepção de utilização da internet em empresa de consultoria de recursos humanos. XXII encontro nacional de engenharia de produção. Curitiba.

Barreto, L. M. T. da S. \& Lima, C. L. de. (2014). Gestão de pessoas na hotelaria: um estudo de caso no Hotel Ponta do Madeiro - Pipa/RN. Anais do XI Seminário da Associação Nacional de Pesquisa e Pós-Graduação em Turismo - ANPTUR, Fortaleza. 
Brandão, J. M. F. (2011). Análise das Práticas de Gestão de Pessoas na Hotelaria: Um Estudo no Verdegreen Hotel, Em João Pessoa-PB. 129f. Monografia (Graduação em Hotelaria) - Universidade Federal da Paraíba, Mamanguape.

Carvalho, F. C. D. de. Et al. (2015). A importância do processo de recrutamento e seleção nas organizações para redução do turnover. V Encontro Científico e Simpósio de Educação Unisalesiano: A pesquisa frente à inovação e o desenvolvimento sustentado. Lins: São Paulo.

Cervo, A. L., Bervian, P. A. \& Da Silva, Roberto. (2007). Metodologia Científica. (6 ${ }^{\mathrm{a}}$ ed.). Editora Pearson.

Cazotto, E. M. de S., Cobero, C. \& Daolio, L. A. (2016). Implantação do processo de recrutamento e seleção em um hotel no interior de São Paulo. XIII SEGET - Simpósio de Excelência em Gestão e Tecnologia.

Chiavenato, I. (2008). Administração Geral e Pública. (2 ${ }^{\mathrm{a}}$ ed.). Rio de Janeiro: Elsevier.

Chiavenato, I. (2014). Gestão de Pessoas, o Novo Papel dos Recursos Humanos nas Organizações. ( $4^{\mathrm{a}}$ ed.). Barueri, SP: Manole.

Duarte, V. M. do N. (2013). Pesquisa Quantitativa e Qualitativa. São Paulo: Saraiva.

Ferreira, S. F. \& Soeira, F. dos S. (2013). A Importância do Recrutamento e Seleção de Pessoas Em Uma Empresa de Pequeno Porte do Setor de Móveis. Revista Eletrônica Diálogos Acadêmicos, 4(1), p. 46-56, JAN-JUN.

Ferreira Filho, F. B. (2013). Um Estudo Sobre a Eficiência do Processo de Seleção Interna do Banco do Nordeste do Brasil S.A (BNB) a Partir da Análise do Modelo de Seleção Por Competência. Faculdade 7 de Setembro. Fortaleza.

Ferreira, F. S. \& Vargas, E. C. (2014). A importância do recrutamento e seleção de pessoas no contexto empresarial. Estação Científica - UNIFAP, 4(2). Macapá.

Freitas, H. et al. (2000). O Método de Pesquisa Survey. Revista de Administração, 35(3), $105-$ 112, julho/setembro. São Paulo.

Gomes, T. C., Scherer, L. A. \& Löbler, M. L. (2012). Uso das redes sociais virtuais no processo de recrutamento e seleção de pessoal: uma análise na perspectiva de profissionais de recursos humanos. Anais, SIMPOI.

Gonsalves, E. P. (2003). Conversas Sobre Iniciação à Pesquisa Cientifica. (3ª ed.). Campinas, SP: Alínea.

Hanashiro, D. M. M., Teixeira, M. L. M. \& Zacarelli, L. M. (2007). Gestão do Fator Humano, Uma Visão Baseada em Stakeholders. São Paulo: Saraiva.

Knapik, J. (2008). Gestão de Pessoas e Talentos. Curitiba: Ibpex.

Lacombe, F. (2005). Recursos Humanos, Princípios e Tendências. São Paulo: Saraiva.

Marras, J. P. (2000). Administração de Recursos Humanos do Operacional ao Estratégico. ( $3^{\mathrm{a}}$ ed.). São Paulo: Futura. 
Marras, J. P. (2011). Administração de Recursos Humanos do Operacional ao Estratégico. 14. edição. São Paulo: Saraiva.

Peternelli, L. A. (2004). Estatística Descritiva. Capitulo 2. São Paulo: Editora Saraiva.

Pierry, F. (2006). Seleção por competências, o processo de identificação de competências individuais para recrutamento, seleção e desenvolvimento de pessoal. São Paulo: Vetor.

Prodanov, C. C. \& Freitas, E. C. de. (2013). Metodologia do Trabalho Científico: Métodos e Técnicas da Pesquisa e do Trabalho Acadêmico. ( $2^{\mathrm{a}}$ ed.). Novo Hamburgo, RS: Feevale.

Santaella, L. A., Santos, A. E. G. \& Rodrigues, J. L. K. (2014). A gestão de Recursos Humanos em empreendimentos do setor hoteleiro na cidade de Taubaté/São Paulo. X Congresso Nacional de Excelência em Gestão.

Vieira, A., Lima, C. H. Pereira \& Pereira, G. B. (2007). Tradição e Modernidade nas práticas de recrutamento e seleção de pessoas em hospedagem. Revista Gestão e Planejamento, 8(2). Salvador. 